\title{
INVESTIGACIÓN
}

Recibido: 14/09/2020 --- Aceptado: 12/12/2021 --- Publicado: 12/03/2021

\section{DOCENTES UNIVERSITARIOS MIGRANTES: UNA MIRADA CUANTITATIVA A UN PROBLEMA CUALITATIVO}

\section{Migrant university teachers: a quantitative look at a qualitative problem}

(8) Audy Salcedo ${ }^{1}$. Universidad Central de Venezuela. Venezuela.

audy.salcedo@ucv.ve

8) Ramón Alexander Uzcátegui Pacheco². Universidad Andrés Bello. Chile. razktgui@gmail.com

\section{RESUMEN}

Para Venezuela la migración es un fenómeno reciente que por su cuantía ha llamado la atención de países y organismos internacionales. Este estudio se centra en docentes universitarios para indagar algunos de los factores que condicionaron su salida del país, determinar sus características laborales y académicas al momento de la migración y explorar elementos de su inserción socio profesional en el país receptor. Se trabajó con una muestra no probabilística de 373 docentes que respondieron un cuestionario en línea. Los resultados indican que la crisis política económica del país motivó su migración. La mayoría salió a partir de 2015. Casi la mitad tiene título de doctor y menos de un tercio trabaja ahora en docencia universitaria, pero señalan que sus condiciones de vida son mejores a las tenían al momento de migrar.

PALABRAS ClAVES: Profesorado - Diáspora - Educación Superior - Carrera Académica - Venezuela.

\section{ABSTRACT}

For Venezuela, migration is a recent phenomenon that due to its amount has attracted the attention of countries and international organizations. This study focuses on university teachers to investigate some of the factors that conditioned their leaving the country, determine their job and academic characteristics at the time of migration, and explore elements of their socio-professional insertion in the host country. We worked with a non-probability sample of 373 teachers who answered an

\footnotetext{
${ }^{1}$ Licenciado en Educación. Doctor en Educación. Profesor Titular Universidad Central de Venezuela, Venezuela.

${ }^{2}$ Licenciado en Educación. Doctor en Humanidades. Profesor Universidad Andrés Bello, Chile.
} 
online questionnaire. The results indicate that the country's economic, political crisis motivated its migration. Most left from 2015. Almost half have a doctorate and less than a third now work in university teaching, but they point out that their living conditions are better than they were when they migrated.

KEY WORDS: Professorship - Diaspora - Higher Education - Academic Career Venezuela.

\section{PROFESSORES UNIVERSITÁRIOS MIGRANTES: UM OLHAR QUANTITATIVO A UM PROBLEMA QUALITATIVO}

\section{RESUMO}

Para Venezuela a migração é um fenômeno recente que pela sua quantidade tem chamado a atenção de países e organismos internacionais. Este estudo está focado nos professores universitários e para procurar alguns dos fatores que condicionaram a sua saída do país, determinar as características dos seus trabalhos e acadêmicas no momento da migração e analisar elementos da sua inserção sócio profissional no país receptor. Foi realizada uma amostra não probabilística de 373 professores que responderam um questionário on-line. Os resultados indicam que a crise política e econômica do país motivou sua migração. A maioria saiu a partir de 2015. Quase a metade tem doutorado e menos de um terço trabalha agora como professor universitário, mas apontam que suas condições de vida são melhores do que as que tinham no momento de migrar.

PALAVRAS CHAVES: Professores, Diáspora, Educação Superior, Carreira Acadêmica, Venezuela

\section{Cómo citar el artículo:}

Salcedo, A. y Uzcátegui Pacheco, R. A. (2021). Docentes universitarios migrantes: una mirada cuantitativa a un problema cualitativo. Vivat Academia. Revista de Comunicación, 154, 101-131. http://doi.org/10.15178/va.2021.154.e1277

http://www.vivatacademia.net/index.php/vivat/article/view/1277

\section{INTRODUCCIÓN}

Venezuela se ha convertido en un país productor de migrantes. Los informes que, desde la Organización de Naciones Unidas (ONU), la Organización de las Naciones Unidas para la Educación, la Ciencia y la Cultura (UNESCO), y la Organización Internacional para las Migraciones (OIM) señalan que es un fenómeno masivo. La Oficina del Alto Comisionado de las Naciones Unidas para los Refugiados (ACNUR) (2019) sostiene que son más de 4,7 millones de personas refugiadas y migrantes de Venezuela en todo el mundo y más de 750.000 venezolanos han solicitados asilo en 
distintos países. Solo esas cifras dan para que el tema de la migración venezolana sea un desafío para la región.

La crisis humanitaria, y en general, el deterioro de la institucionalidad democrática republicana ha llegado a tales niveles, que parte de la población ha decidido salir del país en busca de mejores condiciones de vida. La crisis inducida por la idea de refundar la república e insistir en el establecimiento del socialismo del siglo XXI han afectado gravemente al país en todos los órdenes, han lesionado todas las instituciones sociales, particularmente, en la institucionalidad educativa, al profesorado universitario, en este caso, objeto de nuestra investigación.

Los estudios sobre la migración venezolana han sido de preocupación creciente en el mundo académico como los desarrollado por Osos y Villares, (2005); Mateo y Ledezma, (2006); Rivas, 2009; Echeverry Hernández, (2011); Castillo Crasto y Reguant Álvarez, (2017). En el caso de la migración profesional es importante tener presente los trabajos de De la Vega, (2003); Ibarra Lampe y Rodríguez, (2011); De la Vega y Vargas, (2014); Páez (2010); Zuñiga (2011); Requena y Caputo (2016) y Vargas Ribas (2018), García Arias y Restrepo Pineda, (2019) que han venido caracterizando en problema en los distintos segmentos laborales. En función de ello, la presente investigación se centra en el estudio del profesorado universitario, en tanto que población migrante, definir sus características personales, conocer por qué decidieron migrar, y tener una idea, a partir de sus propias opiniones sobre su vida académica más allá de la frontera nacional. ¿Ha mejorado sus condiciones de vida? ¿Han podido continuar con su carrera académica en los países de acogida? Es parte de lo que en este trabajo de investigación se aborda.

\section{MARCO TEÓRICO}

La OIM, define migración internacional como el movimiento de personas que dejan su país de origen o en el que tienen residencia habitual, para establecerse temporal o permanentemente en otro país distinto al suyo. Para tener una idea "El número de migrantes internacionales aumentó de 93 millones en 1960 a 258 millones en 2017 (UNESCO, 2019, p. 35). Un rasgo de la migración internacional de los últimos años es la facilidad de movilización (Cabieses, Bernales y McIntyre, 2017) y la complejidad de causas que hay en ella.

La migración internacional puede tener diversas causas "Hay 87 millones de personas desplazadas en el mundo: 25 millones de refugiados, 3 millones de solicitantes de asilo, 40 millones de desplazados internos a causa de conflictos y 19 millones a causa de catástrofes naturales" (UNESCO, 2019). Hoy los flujos migratorios reconfiguran el panorama global, los desplazamientos humanos nortesur, ahora son sur-sur, como el caso de la región latinoamericana, donde buena parte de la población ya no migra hacia destinos históricos tradicionales como Estados Unidos o Europa, sino que se mueve dentro del subcontinente en búsqueda de mejores opciones de vida entre países vecinos. 
Venezuela es un caso de migración forzada, la situación a la que ha sido sometida la población producto de la acción gubernamental ha hecho que millones de personas hayan tenido que desplazarse de sus hogares hacia otros países. La pérdida de calidad de vida, la disolución institucional y la violación sistemática de los derechos humanos establecidos en la Constitución de la República Bolivariana de Venezuela de 1999 condiciona las razones por las cuales muchos venezolanos salen del país. La migración "nunca puede considerarse completamente voluntaria" (Davidson, 2003, p. 37). En el caso venezolano persiste una combinación de variables estructurales e individuales, siendo las variables estructurales un factor determinante en la explicación del proceso migratorio (Ibarra Lampe y Rodríguez, 2011). Venezuela figura en las estadísticas de países afectados por ataques contra la educación, el uso militar de instalaciones, o estudiantes o miembros del personal docente herido, según el informe Education Under Attack 2018 de la GCPEA (Citado por UNESCO, 2019, p. 201), este dato contrasta con otros índices donde el país figura en los principales puestos en inflación, inseguridad, seguridad alimentaria, salud, etc.; mientras la crisis se agrava, la cantidad de personas que huyen de Venezuela solo irá en aumento (Mahlke y Yamamoto, 2017); no hay razón para creer que la salida de venezolanos disminuirá en el futuro previsible. (Feline Freier y Parent, 2019)

La migración objeto de nuestra indagación es una migración calificada, entendida como el flujo de personas de un país a otro que cuentan con diplomas de tercer nivel equivalente al grado de licenciatura (OIM, 2018, p. 51). Aunque los criterios pueden variar, pues además de la escolaridad, como bien señala la OIM, puede tenerse en consideración otras variables como el tipo de trabajo que realizaba, la posición ocupacional en la estructura de empleos en el país de origen. La migración calificada no es un fenómeno nuevo (Baeninger y Jarochinski, 2018, p. 335), muchos gobiernos del mundo han diseñado políticas para dar acogida, conforme sus áreas de interés y necesidades de desarrollo talentos de otras sociedades. La migración cualificada puede responder más a una lógica selectiva -necesidades de talento humano, mercado laboral, etc.- que al patrón migratorio venezolano actual donde hay una salida masiva de ciudadanos, muchos en situación de refugiados o desplazados.

Las altas calificaciones que portan refugiados, desplazados y migrantes no son inmediatamente percibidas, reconocidas o convalidadas en el país receptor. La inserción y desarrollo profesional del grupo humano que conforma la migración puede verse limitada por barreras legales, idiomáticas, culturales y de certificación. Para las personas "el reconocimiento de sus cualificaciones constituye un impedimento más, que los inmigrantes suelen considerar como más difícil de superar que las barreras lingüísticas (Eurostat, 2014, citado por UNESCO, 2019, p. 103). Esto supone un reto para los migrantes que disponen de altos niveles de escolarización o que desempeñan labores universitarias. Esta situación impacta de forma directa en la persona, en su autoestima, en la posibilidad de insertarse laboralmente en los países de acogida, "Más de un tercio de los inmigrantes residentes en países de la Organización de Cooperación y Desarrollo Económicos (OCDE) están sobre cualificados para los empleos que ocupan, en comparación con el $25 \%$ de la población nativa" (OCDE/Unión Europea, 2015; citado por UNESCO, 2019, p. 103)

Vivat Academia. Revista de Comunicación. 2021, nº 154, 101-131 
La migración calificada en Venezuela es un fenómeno que se registra en la década de los años 1990 y 2000, la diferencia con aquellos momentos es que más que un proceso selectivo de los profesionales hoy es un fenómeno masivo de salida general del país. Las causas más comúnmente citadas son "las grandes diferencias en la calidad de vida y en las condiciones laborales de desempeño del profesional" (Requena y Caputo, 2016, p. 445). Hoy día está asociada a la crisis general de la institucionalidad venezolana, al punto de ser considerada crisis humanitaria.

El caso venezolano no es precisamente una fuga de cerebros, es en todo caso, expulsión de cerebros frente a la forma como se han administrado los asuntos públicos del país, a la gestión del sistema universitario y al modelo de desarrollo de ciencia y tecnología. Hasta 1999 era más el número de venezolanos que ingresaban al sistema de investigación que los que salían, a partir de 2000 "esa situación cambio y el flujo neto se hizo negativo" (Requena y Caputo, 2016, p. 449). Ciertamente, esta salida representa un vaciamiento de la institucionalidad venezolana (Uzcátegui, Guzmán y Bravo, 2018), mermando la capacidad de sus fuerzas creativas, "la emigración calificada afecta negativamente al país de origen por distintas vías, entre las que se destacan el crecimiento económico, el comercio internacional, la inversión en educación, el aporte fiscal y la transferencia de conocimientos y tecnología" (Abella, 2006, citado por OIM, 2018, p. 43). Esta situación puede ser revertida si se capitaliza la experiencia internacional para el fortalecimiento de las capacidades en el país de origen, "Estas experiencias y contactos son recursos muy valiosos para el país de origen de los talentos, siempre que existan las oportunidades para que puedan aplicar allí sus habilidades" (Arocena y Sutz, 2006 citado en OIM, 2018, p. 44).

El profesorado universitario es parte de la migración calificada que salió de Venezuela en los últimos años, estos han visto interrumpida su carrera académica. La carrera académica forma parte del proceso de modernización de la universidad venezolana en el siglo XX (Parra Sandoval, 2003). Por Ley de Universidades, el cuerpo docente no son solo trasmisores de conocimiento, sino también creadores de conocimiento (Morles, Medina y Álvarez, 2003), su escenario son las instituciones de educación superior. La posibilidad de ejercer la docencia, sumado a la investigación y la extensión a dedicación exclusiva y tiempo completo forma parte de la estrategia de fortalecer no solo la universidad, sino también el sistema venezolano de creación de conocimiento, investigación e innovación.

En 2014 ya comienza a percibirse con fuerza un movimiento migratorio del sector universitario. El directivo de la Asociación de Profesores de la Universidad Central de Venezuela, Gregorio Alfonzo, cuantificó 834 renuncias entre 2008 hasta 2011, "Este año 11 Doctores de la Facultad de Ciencias emigraron, El éxodo docente en 2014 puede llegar a 220". (Méndez, 2014, El Universal); “Los mejores salarios y condiciones que ofrecen países como Ecuador, Colombia, México, Chile y Brasil han acentuado la migración de millares de docentes (Méndez, 2014, El Universal). El representante gremial Tulio Olmos señala que "Los profesores quieren vivir de forma decente y la universidad no se los garantiza" (Méndez, 2014, El Universal). Esta 
situación no es solo exclusiva del profesorado universitario, en educación básica también hay un creciente número de maestros que huyen del país. (Montilla, 2014, 08 de diciembre).

Desde 2007, el gobierno de Venezuela mantiene a las universidades con el mismo presupuesto. Todos los años cada universidad envía un presupuesto sustentando en sus distintas necesidades, pero el gobierno de Venezuela rechaza el presupuesto y asigna la misma cantidad que en año 2007, es lo que se denomina presupuestos reconducidos. Para cubrir las diferencias de cada año, las universidades dependen de los llamados créditos adicionales, la asignación, de forma unilateral, de parte del gobierno de montos extras. Eso créditos adicionales se asignan varias veces en el año pero sin ninguna planificación. Esta dinámica no se corresponde con la dinámica institucional de las universidades, ni con la macroeconómica del país afectado por una inflación crónica de más de tres dígitos al año. En 2020 señala Benjamín Scharifker, rector de la Universidad Metropolitana "que la deserción estudiantil y profesoral ronda en promedio 40\%" (Descifrado.com, 2020, 8 de marzo) lo que representa un verdadero éxodo de talentos en el sector.

El carácter forzado de la migración venezolana se puede constatar en los informes elaborados por los organismos oficiales dedicados a la materia. En Brasil, por ejemplo, el subcomité federal para la interiorización de los migrantes señaló que 27\% de los hombres que llegan al país carioca lo hacen por razones de abrigo, refugio, un 9\% de la población masculina lo hace por búsqueda de empleo. Señala el informe que buena parte de los venezolanos, $83 \%$ viaja con su grupo familiar, lo que expresa un fuerte componente de movilización de personas hacia el vecino país (ONUMigración, 2019). Entre 2013 y diciembre de 2019 “264.000 venezolanos han solicitado refugio o residencia en Brasil, la gran mayoría de ellos entrando por Roraima" (Fundação Getulio Vargas - FGV, 2020). Como señala el informe "Este flujo no tiene precedentes en términos regionales debido al importante volumen de personas que 'están migrando' en este momento por toda la región sudamericana en busca de su supervivencia" (FVG, 2020: 23). Estas cifras en Brasil es una parte del problema, según la plataforma Refugee and Migrant Response Plan (RMRP) "En octubre de 2019, más de 4,5 millones de refugiados y migrantes de Venezuela se encuentran fuera de su país de origen, y 3,7 millones de ellos se encuentran en la región solamente" (RMRP, 2020). Las proyecciones para 2020 es de 5,5 millones de venezolanos fuera de su país (RMRP, 2020).

Las primeras oleadas migratorias de venezolanos se dirigieron a EE. UU. y Europa, los últimos años ha habido un cambio en el patrón migratorio, hay un aumento significativo de migrantes hacia sur América. La distribución de venezolanos en la región ha impactado las sociedades latinoamericanas. En 2017 "Colombia cuenta con alrededor de 600.000 migrantes venezolanos. En América Central y el Caribe, el número de nacionales venezolanos se duplicó de alrededor de 50.000 en 2015 a casi 100.000 actualmente" (OIM, 2019, p. 3). Chile reporta a diciembre de 2018 que los venezolanos son el grupo más numeroso de migrantes que tiene el país, de 1.251.225 de personas extranjeras, 23\% son venezolanos, la cifra en 
ese momento ascendía a 288.233 venezolanos establecidos en el país austral (INE, 2019). Hasta diciembre de 2019 la distribución de venezolanos en el subcontinente es la siguiente Colombia 1.600.000, Ecuador 385.000, Perú 863.600, Chile 371.200, Brasil 224.100, Argentina 145.000, Uruguay 13.700 y Paraguay 3.800. En América Central y México: Panamá 94.600; México 71.500; Costa Rica 28.900 (R4V, 2019). Los órganos internacionales estiman que en 2020 este fenómeno no se revertirá, sino que se intensificará.

\section{METODOLOGÍA}

Desde el punto de vista metodológico se trata de una investigación descriptiva y de campo, realizada con la técnica de la encuesta, para ello se diseñó un cuestionario semiestructurado, que incorporaba preguntas abiertas y cerradas. Se utilizaron parámetros cuantitativos y cualitativos en el tratamiento de los datos, por lo que puede considerarse investigación mixta, en la cual se busca identificar precisar las características personales y académicas de una muestra de profesores universitarios, las razones por las cuales decidieron emigrar de Venezuela.

La investigación se ha desarrollado distendidamente en el tiempo, a los fines de cubrir con los objetivos de esta. Esto implicó, revisión documental, lectura de informes, consulta en prensa para hacerse de un referente sobre el tema planteado. La migración venezolana se ha convertido en un objeto de investigación para distintos grupos y universidades de la región. Esta primera revisión nos aproximó a nuestro objeto específico de análisis, el profesor universitario, tal decisión se hace en un contexto en el cual se planteó la preocupación pública por el vaciamiento de la institucionalidad educativa, más específicamente, de la migración de docentes de los diferentes niveles del sistema escolar venezolano.

Se diseñó un cuestionario de 56 preguntas, algunas de selección múltiples, otras abiertas de modo que el encuestado pudiere emitir su razonamiento frente a lo planteado. Se consideraron las siguientes variables: identificación del profesor, aspectos afectivos-familiares, situación laboral antes y después de salir de su país; situación en su carrera académica, decisión u opción por migrar, proceso migratorio y vínculos con Venezuela. Con ello se busca indagar algunos de los factores que condicionaron su salida del país, determinar sus características laborales y académicas al momento de la migración y explorar elementos de su inserción socio profesional en el país receptor.

El tratamiento de las preguntas cerradas fue cuantitativo, de modo de establecer frecuencias y porcentajes representativos de los enunciados planteados. Las preguntas abiertas fueron tratadas cualitativamente, se trabajaron a partir análisis ideas críticas, con lo cual se leyó cada uno de los planteamientos hechos por los entrevistados; las respuestas, frases de las personas encuestadas, se agruparon, se organizaron en clúster de respuestas a los cuales se les asignó descriptores, palabras claves que luego se conceptualizaron como categorías de análisis. Las categorías de dedujeron de las respuestas dadas por las personas encuestadas. Este proceso de 
categorización implicó un proceso de lectura, selección de recurrencias, y organización de frases, que dieran formas a párrafos sustantivos para la investigación. A partir de tales agrupaciones se identificaron ideas, proposiciones y conceptualizaciones que desde el profesorado migrante ayudan a caracterizar su situación, de la universidad, del país de acogida y de Venezuela.

El cuestionario fue validado por 5 especialistas en estos temas y además por 5 metodólogos, una vez que emitieron opinión, se introdujeron pequeñas modificaciones ajustando de ese modo el cuestionario. El instrumento se diseñó y se administró desde una plataforma virtual, tuvo un tiempo de disponibilidad de tres meses, durante el cual se invitó al personal docente a participar. Este formato garantiza que no haya duplicación de información, ya que el llenado lo hacen las personas participantes desde su correo electrónico, además facilita el contacto con informantes en muy diversas localidades.

Se usó el muestreo por bola de nieve, una técnica de muestreo no probabilística que se usa con frecuencia para acceder a poblaciones de baja incidencia y a individuos de difícil acceso por parte del investigador. Luego de identificar los primeros sujetos, se le pide ayuda para ubicar a otras personas que tengan un perfil similar. En este caso, se partió de una lista de correos del cuerpo docente que se sabía había emigrado y se les envió el link del cuestionario, junto al consentimiento informado para participar en la investigación, explicando los objetivos, así como sus derechos y responsabilidades como posible persona participante; además de garantizar el carácter confidencial de los datos obtenidos y su uso exclusivo para la investigación. Luego de responder el cuestionario a las personas participantes se les pedían sugerir nombre y direcciones de correo de otros docentes de los cuales tenían la certeza habían emigrado. Asimismo, se le solicitaba invitaran a colegas a llenarla, dada su condición de migrante.

La aplicación utilizada reporta marca temporal, el registro de la hora y fecha que fue respondido cada cuestionario, esto permitió controlar los momentos de inicio y cierre del proceso de recolección de datos. Entre agosto y octubre de 2018, se reunieron 373 cuestionarios totalmente respondidos. La muestra quedó conformado por un $50 \%$ de personas de sexo femenino, con edades comprendidas entre 25 y 81 años. El $71 \%$ de las personas consultadas son casados. Sobre la información contactada, procedimos a un primer análisis descriptivo, que como señalamos al comienzo de este artículo, nos permitiera perfilar los rasgos del cuerpo docente venezolano migrante que participaron en la investigación.

\section{RESULTADOS}

\subsection{Características personales}

La nacionalidad fue el primer aspecto consultado, el 100\% manifestó ser venezolano, la casi totalidad por nacimiento. Solo 8 personas indicaron que eran venezolanos pero nacidos en otro país, lo cual significa que ser venezolano era su 
segunda nacionalidad. La tabla 1 muestra la distribución de las nacionalidades del $28,4 \%$ de las personas que indicaron tenían una segunda nacionalidad, distinta a la venezolana.

Tabla 1. Segunda Nacionalidad

\begin{tabular}{|l|r|r|}
\hline Nacionalidad & \multicolumn{1}{|c|}{$\mathrm{N}$} & \multicolumn{1}{|c|}{$\%$} \\
\hline Española & 41 & 11,0 \\
\hline Italiana & 22 & 5,9 \\
\hline Colombiana & 10 & 2,7 \\
\hline Portuguesa & 7 & 1,9 \\
\hline Chilena & 6 & 1,6 \\
\hline Norte Americana & 5 & 1,3 \\
\hline Ecuatoriana & 2 & 0,5 \\
\hline Cubana & 2 & 0,5 \\
\hline Argentina & 2 & 0,5 \\
\hline Uruguaya & 1 & 0,3 \\
\hline Salvadoreña & 1 & 0,3 \\
\hline Peruano & 1 & 0,3 \\
\hline Noruego & 1 & 0,3 \\
\hline Holandés & 1 & 0,3 \\
\hline Dominicana & 1 & 0,3 \\
\hline Canadiense & 1 & 0,3 \\
\hline Británica & 1 & 0,3 \\
\hline Alemana & 1 & 0,3 \\
\hline Total & 106 & 28,4 \\
\hline
\end{tabular}

Fuente: Elaboración propia

Las cuatro nacionalidades que destacan son: española, italiana, colombiana y portuguesa; todas nacionalidades de tradicional acogida cuando Venezuela era un país receptor de migrantes. En los años 50's y 60's era común en Venezuela la llegada de españoles, italianos y portugueses. Los 70's llegaron grandes oleadas de migrantes colombianos atraídos por la situación económica del país y la difícil situación que vivía Colombia producto de la acción de los grupos guerrilleros. En esos años Venezuela también fue receptora de migrantes que huían de las dictaduras del cono sur. En los estudios de migración, conocer si los sujetos migrantes poseen una segunda nacionalidad es relevante ya que es una medida para conocer los flujos migratorios históricos y recientes. Con relación a este aspecto, el 71,4\% reportó que solo posee la nacionalidad venezolana, lo que indica que probablemente son migrantes por primera vez, y que probablemente, o potencialmente, asuman una segunda nacionalidad en el curso de su vida, extendiéndose así, el ejercicio de la ciudadanía en los países de acogida. El grafico 1 muestra la distribución de las edades del grupo considerado. 


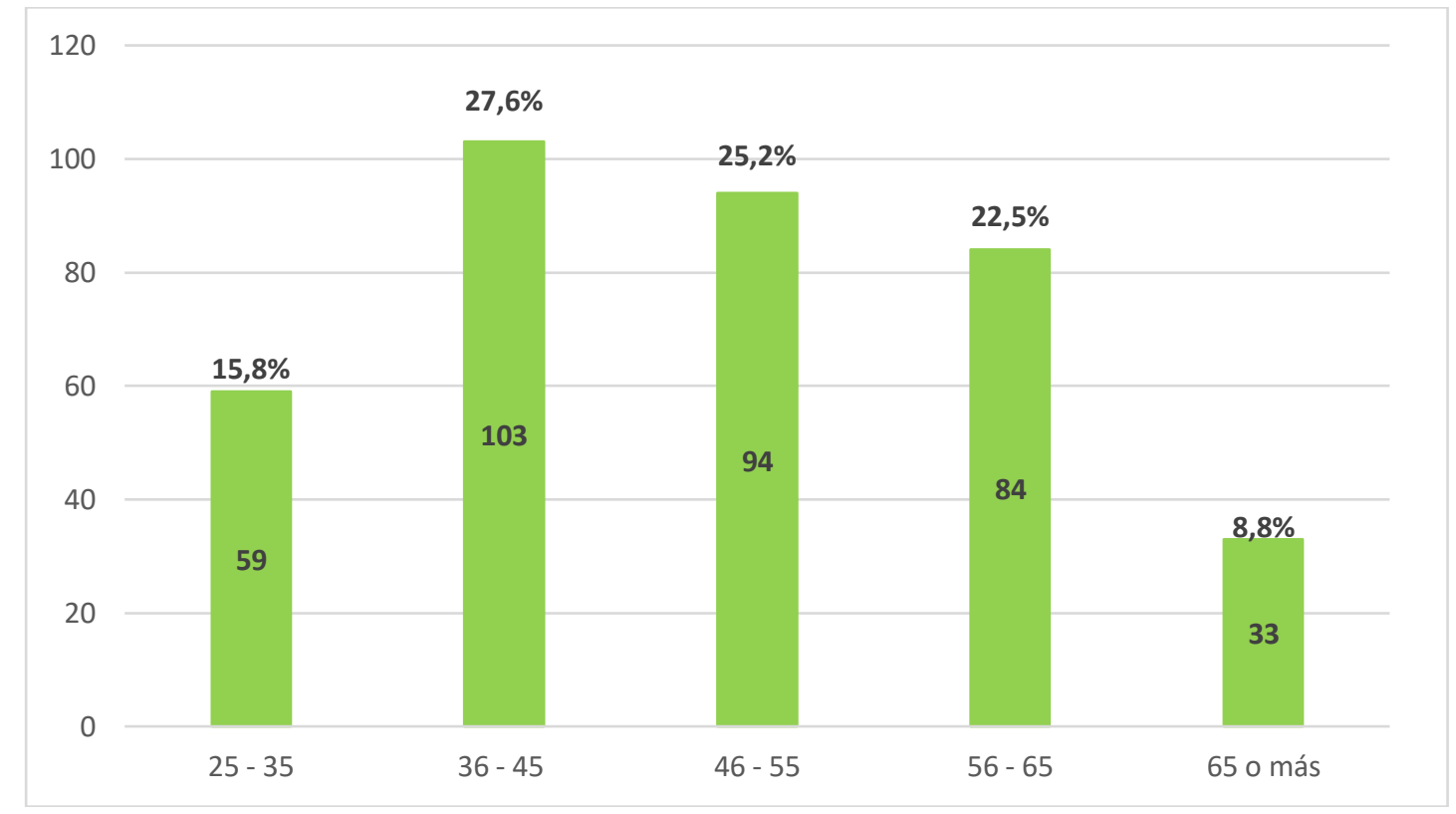

Gráfico 1. Edad del cuerpo docente migrante

Fuente: Elaboración propia

El grupo es fundamentalmente joven, el 68,6\% manifestó tener 55 años o menos. En términos globales, estamos ante la presencia de una muestra de docentes universitarios en edad activa, que están en plena edad para el desarrollo de su carrera académica. Los docentes migrantes venezolanos representan un segmento de población joven con desarrollo potencial a engrosar posiblemente los sistemas profesionales y universitarios en los países de acogida o receptores.

En relación con la ciudad de residencia, el 63,8\% indicó que vivía en la denominada Gran Caracas (Caracas y ciudades aledañas). En la Venezuela de ese momento eso significaba mejores servicios públicos, mayores índices de abastecimiento de comida y medicina pero también mayores índices de inseguridad personal.

\subsection{Aspectos socioafectivos del profesorado universitario migrante}

En la investigación se consideró relevante consultar al personal docente universitario migrante sobre su situación socioafectiva, tanto al salir de Venezuela, como en el país de acogida. Esta dimensión incorporó varios ítems, uno de ellos aborda cuáles miembros de la familia están actualmente con él o ella en el país de acogida. La respuesta fue variada, ya que se dio oportunidad de listar las personas del grupo familiar que se encuentra con el encuestado. La lista de familiares nombrados es variada, va desde esposa e hijos, hasta cuñados y sobrinos, pasado por padres, abuelos y nietos. La tabla 2 muestra las categorías que se generaron para agrupar los distintos familiares que nombrado por el grupo participante.

Tabla 2. Miembros de la familia con los que actualmente vive 
Salcedo, A. y Uzcátegui Pacheco, R. A.

Docentes universitarios migrantes: una mirada cuantitativa a un problema cualitativo

\begin{tabular}{|l|r|r|}
\hline & $\mathrm{N}$ & \multicolumn{1}{|c|}{$\%$} \\
\hline Ninguno / se encuentra solo & 33 & $8,8 \%$ \\
\hline Esposo / esposa/Pareja/Novia/Novio & 50 & $13,4 \%$ \\
\hline Esposo / esposa, hijos & 82 & $22,0 \%$ \\
\hline Esposo / esposa, hijos, madre, padre & 22 & $5,9 \%$ \\
\hline Esposo / esposa, hijos, nietos & 13 & $3,5 \%$ \\
\hline Esposo / esposa, hijos, hermanos & 18 & $4,8 \%$ \\
\hline Esposo / esposa y suegros & 11 & $2,9 \%$ \\
\hline Hijos & 24 & $6,4 \%$ \\
\hline Hijos, madre, padre. abuelos & 17 & $4,6 \%$ \\
\hline Hijos, nietos & 8 & $2,1 \%$ \\
\hline Madre, padre, abuelos y hermanos & 55 & $14,7 \%$ \\
\hline Hermanos y sobrinos & 29 & $7,8 \%$ \\
\hline Tíos, primos, cuñados & 11 & $2,9 \%$ \\
\hline & 373 & $100,0 \%$ \\
\hline
\end{tabular}

Fuente: Elaboración propia

Lo primero que destaca es que el profesorado encuestado no migró solo, en mayor porcentaje van con uno o más familiares cercanos. Menos del 10\% de ellos señaló que se encontraba solo en el país de acogida. Más del 50\% indicó que se encuentra con su pareja o cónyuge y algún otro familiar; destacando el grupo de familiares directos Esposo/esposa e hijos. También destaca el porcentaje de migrantes que se encuentra viviendo con sus padres. Un poco más del $20 \%$ señala que se encuentra con sus padres en el país al cual emigró. Estos resultados concuerdan con lo señalado por Cohen (2001), en cuanto a que los migrantes suelen involucrar algún familiar o coterráneo.

Un segundo ítem asociado a la situación afectiva del profesor universitario está relacionado con conocer con cuáles miembros de su grupo familiar no vive actualmente. En las respuestas muchos manifestaron que buena parte de su grupo familiar estaba en Venezuela, otros, ya han migrado a otros países. Destaca en la respuesta que en su mayoría del profesorado no viven actualmente con sus padres; un grupo señaló que no está con sus parejas, hijos. Son migrantes que no está conviviendo con parte de su grupo familiar más cercano. En las respuestas dadas, el cuerpo docente señala también que están lejos de sus abuelos, nietos, sobrinos, hermanos, cuñados, etc. El hecho de tener una parte de su familia en Venezuela podría generar preocupaciones al migrante, dada la situación política, económica y social del país.

Tabla 3. Miembros de la familia con los que no vive actualmente

\begin{tabular}{|l|c|c|}
\hline & $\mathrm{N}$ & $\%$ \\
\hline Madre, Hermanos, Sobrinos & 182 & $48 \%$ \\
\hline
\end{tabular}


Salcedo, A. y Uzcátegui Pacheco, R. A.

Docentes universitarios migrantes: una mirada cuantitativa a un problema cualitativo

\begin{tabular}{|c|c|c|}
\hline Hijos, Madre, Padre & 75 & $20 \%$ \\
\hline Hermanos, Sobrinos, Cuñados & 43 & $12 \%$ \\
\hline Abuelo, Hermanos, Sobrinos & 37 & $10 \%$ \\
\hline Esposo, esposa, hijos & 32 & $9 \%$ \\
\hline Ninguno & 4 & $1 \%$ \\
\hline Total & 373 & $100 \%$ \\
\hline
\end{tabular}

Fuente: Elaboración propia

\subsection{Flujo migratorio del profesor universitario venezolano}

¿Cómo ha sido el flujo migratorio del profesor universitario?, este es un aspecto relevante en la investigación ya que nos permite caracterizar: el tiempo transcurrido desde su salida de Venezuela, los países a los que se ha dirigido, el medio de transporte empleado al migrar y el espacio de vivienda actual. Al respecto, al consultarse la fecha que partieron de Venezuela se registran datos extremos de sujetos que salieron en 1986 y 1998. Salvo estos casos, la muestra es evidencia de la tendencia que ha caracterizado la dinámica migratoria venezolana de los últimos años. Registrándose los años 2005, 2007 y 2011 picos importantes de salidas, años en los que se registran importantes acontecimientos en la dinámica sociopolítica venezolana. La tendencia se sostiene, con una abrupta pendiente ascendente a partir de 2012 donde el crecimiento ha sido exponencial. En octubre de ese año, Hugo Chávez Frías gana de nuevo la presidencia de la república, aunque con serios señalamientos de fraude. El año siguiente se anuncia la muerte del presidente Chávez y se hacen nuevas elecciones, donde el candidato del partido de gobierno, Nicolás Maduro, se proclama ganador, de nuevo con señalamientos de fraude. En ese marco inicia la mayor oleada de migración universitaria venezolana que se conozca.

De las 373 personas entrevistados, 299 salieron entre 2015 y 2018, año en el se recolectó la información. Esto coincide con un recrudecimiento de la crisis universitaria, las movilizaciones estudiantiles, la crisis humanitaria y la ruptura del Estado de derecho con el llamado a una constituyente -aun en funcionamiento- y la reelección -por mecanismos y resultados cuestionados- de un nuevo mandato presidencial para Nicolás Maduro. 
Salcedo, A. y Uzcátegui Pacheco, R. A.

Docentes universitarios migrantes: una mirada cuantitativa a un problema cualitativo

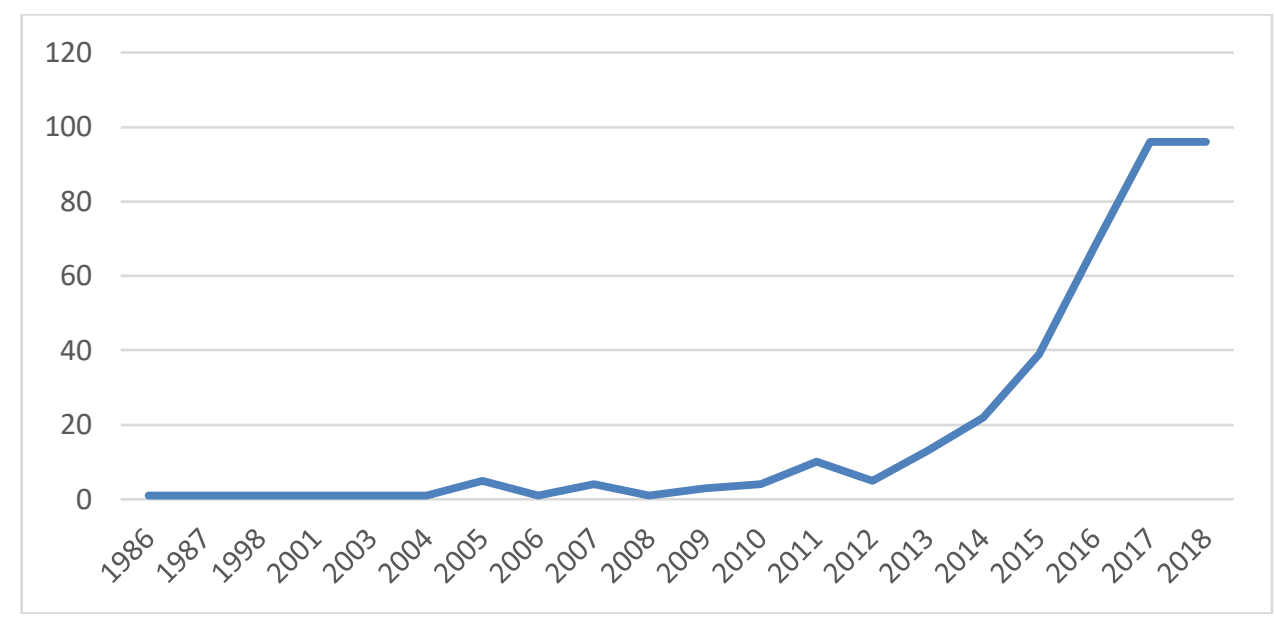

Gráfico 2. Año de salida de Venezuela

Fuente: Elaboración propia

¿A dónde se ha dirigido el personal docente universitario? Este es un aspecto importante dentro de la investigación porque describe el movimiento seguido por los profesionales. La información recogida evidencia que el patrón seguido es el que ha predominado en los últimos años sobre el tema venezolano, migración hacia el sur del continente. La tabla 4 recoge el flujo migratorio de los destinos seleccionados.

Tabla 4. País de destino

\begin{tabular}{|c|c|c|c|}
\hline Región & $\mathbf{N}$ & País & $\mathbf{N}$ \\
\hline \multirow{2}{*}{ Norteamérica } & \multirow{2}{*}{43} & Canadá & 5 \\
\hline & & Estados Unidos & 38 \\
\hline \multirow{17}{*}{ Suramérica } & \multirow{17}{*}{245} & Argentina & 30 \\
\hline & & Brasil & 10 \\
\hline & & Chile & 46 \\
\hline & & Colombia & 38 \\
\hline & & Costa Rica & 5 \\
\hline & & Curazao & 1 \\
\hline & & Ecuador & 62 \\
\hline & & Grenada West Indies & 1 \\
\hline & & Guatemala & 1 \\
\hline & & Guyana & 1 \\
\hline & & Honduras & 1 \\
\hline & & México & 16 \\
\hline & & Panamá & 9 \\
\hline & & Perú & 14 \\
\hline & & Puerto Rico & 2 \\
\hline & & República Dominicana & 2 \\
\hline & & Uruguay & 6 \\
\hline Europa & 85 & Dinamarca & 1 \\
\hline
\end{tabular}


Salcedo, A. y Uzcátegui Pacheco, R. A.

Docentes universitarios migrantes: una mirada cuantitativa a un problema cualitativo

\begin{tabular}{|l|r|l|r|}
\hline & & Alemania & 1 \\
\cline { 3 - 4 } & & España & 65 \\
\cline { 3 - 4 } & & Francia & 5 \\
\cline { 3 - 4 } & & Italia & 4 \\
\cline { 3 - 4 } & & Portugal & 2 \\
\cline { 3 - 4 } & & Reino Unido & 5 \\
\cline { 3 - 4 } & & Suecia & 1 \\
\hline Asia & 1 & Japón & \\
\hline Total & 373 & & \\
\hline
\end{tabular}

Fuente: Elaboración propia

Para las personas migrantes de esta muestra, España y Ecuador son los países con mayor recepción. En el primer caso podría explicarse por la vinculación familiar, mientras el segundo podría ser debido al Programa Prometeo de ese país, que ofrecía sueldos altos en comparación con los bajos salarios del profesorado venezolano. Otros países que destacan son Chile, Colombia, Estados Unidos y Argentina. Los principales países destino de esta muestra coinciden con los países que declaran los venezolanos como preferidos para emigrar (Consultores 21, 2019).

Se consultó cuánto tiempo estima estar en el país de acogida. Se obtuvieron 310 datos válidos, y una serie de comentarios que expresan de cierta forma las proyecciones del profesor en el país de acogida y la situación futura de Venezuela. La tabla 5 recoge las respuestas categorizadas.

Tabla 5. Tiempo estimado en el país de acogida

\begin{tabular}{|c|c|c|}
\hline & $\mathrm{N}$ & $\%$ \\
\hline Más de 5 años & 142 & $46 \%$ \\
\hline 3 a 5 años & 63 & $20 \%$ \\
\hline No sé & 37 & $12 \%$ \\
\hline Indefinido & 32 & $10 \%$ \\
\hline 2 años & 25 & $8 \%$ \\
\hline 1 año & 9 & $3 \%$ \\
\hline Sin información & 2 & $1 \%$ \\
\hline Total & 310 & \\
\hline
\end{tabular}

Fuente: Elaboración propia

Más de la mitad del grupo encuestado indican que podrían pasar al menos tres años. El tiempo de estancia suele ser inversamente proporcional a las posibilidades de retorno. Una estancia más prolongada ofrece las posibilidades de asentar bases en el país de acogida, bajando las probabilidades de retorno a Venezuela.

Sobre las razones que llevarían a permanecer más tiempo en el país de acogida, las respuestas fueron variadas, pero destaca el cómo se perciban los cambios en 
Venezuela. Se hace énfasis en los cambios que observen en la sociedad venezolana y la percepción de que tales cambios signifiquen una mejoría que hagan factible el retorno. Según Dumont y Spielvoge (2008), la migración de retorno engloba cuatro dimensiones: país de origen, lugar de residencia en el extranjero, duración de la estancia en el país de acogida y duración de la estancia en el país de origen cuando se retorna. Las respuestas ofrecidas involucran a tres de esas dimensiones, dejando abierta la posibilidad de retornar.

Desde la perspectiva del venezolano que sigue en su país, sus coterráneos regresará solo si la situación cambia $(45 \%)$, pero un $35 \%$ consideran que no regresarán (Consultores 21, 2019). Así, el asunto de estimación del tiempo de estancia en el país de acogida, más que un asunto de tiempo cronológico refiere más al tiempo histórico social de Venezuela, de su evolución política, y de la percepción de que mejoren las condiciones por las cuales decidieron partir.

\subsection{Migrar: una opción del profesorado universitario venezolano}

La situación de crisis que vive la sociedad venezolana llevó a muchos de sus ciudadanos a tomar la decisión de migrar. La posibilidad de explorar una situación mejor a la que se vive actualmente en el país caribeño llevó a muchos de sus profesionales, y particularmente, al profesorado migrante a emprender nuevas opciones de vida en el extranjero. Ya la situación se ha convertido en un verdadero reto para la región, pues la migración ha tenido diversas oleadas, rostros e impacto en los países de acogida. Según la OCDE (2019), los países con mayor número de migrantes son Afganistán, Siria, Iraq y Venezuela, lo que ubica a Venezuela en el cuarto lugar a nivel mundial. Además, la Agencia de la ONU para los Refugiados (ACNUR, 2019), señala que el éxodo de los venezolanos es el más grande en la historia reciente de América del Sur.

En ese contexto de diáspora, conocer las razones por las cuáles decidieron salir del país es un aspecto relevante, así como a qué está asociada esa decisión. A los docentes se les solicitó, tres razones por las cuáles había decidido salir de Venezuela, como opciones de respuesta tenían políticas; económicas; inseguridad; alimentaria; laborales; salud; reunificación familiar y otros, donde debía precisar la razón que lo llevó a emigrar. Los resultados se muestran en la tabla 6.

Tabla 6. Razones por las cuales decidió migrar

\begin{tabular}{|l|r|r|r|}
\hline \multicolumn{1}{|c|}{ Opciones } & \multicolumn{1}{c|}{ Razón I } & \multicolumn{1}{c|}{ Razón II } & \multicolumn{1}{c|}{ Razón III } \\
\hline Políticas & 235 & 0 & 0 \\
\hline Económicas & 107 & 204 & 0 \\
\hline Inseguridad & 18 & 101 & 162 \\
\hline Laborales & 4 & 15 & 43 \\
\hline Otros & 3 & 0 & 0 \\
\hline Salud & 2 & 6 & 24 \\
\hline
\end{tabular}


Salcedo, A. y Uzcátegui Pacheco, R. A.

Docentes universitarios migrantes: una mirada cuantitativa a un problema cualitativo

\begin{tabular}{|l|r|r|r|}
\hline Reunificación Familiar & 2 & 6 & 28 \\
\hline Alimentación & & 16 & 55 \\
\hline & 371 & 348 & 312 \\
\hline
\end{tabular}

Fuente: Elaboración propia

Como puede observarse entre las razones señaladas por el personal docente predominan tres, razones políticas, económicas y de inseguridad. Poniendo el acento en la situación general del país, el motivo principal de su salida. Queda como cuarta opción su situación laboral en la universidad, claro está, fuertemente condicionada por las variables anteriores.

Escapar de zonas de conflicto es una de las causas más antiguas y más comunes para la migración. Esto puede aplicarse en el caso venezolano. Como se mencionó antes, los datos se recolectaron a mediados del 2018, los venezolanos habían transitado por un 2017 con más de tres meses de protestas y unos 120 ciudadanos asesinados en acciones en torno a esas protestas. Además, ese mismo año, el Gobierno de Nicolás Maduro impulsó la Asamblea Nacional Constituyente con la posibilidad de hacer una nueva constitución. Todo ello colaboraba a un clima político de inestabilidad, que si se une a la inseguridad personal (tercera razón) se tiene un país en permanente disputa, que puede considerarse como una zona de conflicto. Es la necesidad de la persona de ubicarse en entornos más seguros, lejos de lo que considera violencia, en este caso política y personal.

Las razones económicas aparecen como la segunda más señalada para salir del país pero también se encuentra como la más frecuentemente elegida en el segundo lugar, lo que es evidencia su peso para motivar la migración. Lo económico es otra de las razones tradicionales de la migración en el mundo: la búsqueda de mejores ingresos que le permitan mejorar sus vidas. Para el memento de la recolección de datos, además de bajos sueldos el país vivía con altos niveles de inflación y de escases de alimentos y medicinas, además de un colapso de los servicios públicos. Esa situación no ha cambiado mucho y según el Bloomberg Misery Index de 2019, Venezuela era el país del mundo con la peor combinación de tasa de desempleo e inflación, más de 8.000.000\%, (Jamrisko y Saraiva, 2019) lo que da una idea de la grave situación del país. En febrero 2020, el Banco Central de Venezuela, ofreció de nuevo cifras económicas (no las publicaba desde 2016) y reconoció una inflación del 9.585\%, mayor que la anunciada por la Asamblea Nacional, de mayoría opositora, para el mismo lapso: $7.374 \%$. Indistintamente de las diferencias y las posibles dudas de las cifras oficiales, Venezuela sigue teniendo la inflación más alta del mundo y continúa en hiperinflación, por lo tanto, razón suficientes para migrar.

Las razones por las que decidieron migrar son de tipo familiar: "Estado de salud de mi madre"; "Estado de salud de mi madre en el exterior"; "ayudar a mis nietos a salir del país"; proyecto de vida y familia: "Cuidado de los nietos"; "Iniciar un nuevo ciclo de vida"; "Deterioro de la Calidad de Vida y principios fundamentales"; "tuve un bebé cuando 
estaba fuera del país y no volví; "Para poder pensar en tener hijos teníamos que salir"; "Venezuela no es sitio para educar a niños pequeños"; "Mi esposo desea emigrar"; "Inestabilidad para mi Futuro"; razones de tipo sentimental "inicié una relación sentimental con un extranjero y su país en ese momento nos ofrecía mejores condiciones a los dos". La lista de razones es más amplia, conforme lo dicho por las personas encuestadas.

Cuando se consultó directamente sobre las razones asociadas a su decisión de migrar, señalaron:

Tabla 7. La decisión de migrar

\begin{tabular}{|l|c|c|c|}
\hline \multicolumn{1}{|c|}{ Opciones } & Razón I & Razón II & Razón III \\
\hline Búsqueda de un mejor futuro & 265 & 0 & 0 \\
\hline Optar por nuevas condiciones de vida & 58 & 122 & 113 \\
\hline Rescate del poder adquisitivo & 34 & 136 & 0 \\
\hline Otros & 12 & 0 & 0 \\
\hline Nuevos Horizontes profesionales & 5 & 26 & 33 \\
\hline Desarrollar / continuar mi carrera académica como profesor & 4 & 28 & 43 \\
\hline Búsqueda de mejores condiciones para investigar & 2 & 8 & 60 \\
\hline Dedicarme a una profesión distinta & 1 & 7 & 12 \\
\hline Calidad de Vida Personal & 0 & 1 & 0 \\
\hline Buscar otras alternativas laborales & 0 & 0 & 1 \\
\hline
\end{tabular}

Fuente: Elaboración propia

Cuando se le solicita especificar las razones de su migración, el grupo encuestado señala como las principales: Búsqueda de un mejor futuro, Rescate del poder adquisitivo y Optar por nuevas condiciones de vida. Todas ellas se relacionan con las esgrimidas en la pregunta anterior: políticas, económicas, inseguridad y laborales. Migrar es la esperanza de encontrar mejorares condiciones económicas que lleven a un nivel de vida más alto, para el migrante y su familia (Stark y Taylor, 1991; Izcara, 2010).

\subsection{La carrera académica}

El profesor universitario en Venezuela es un profesional que se ha dedicado a la docencia, la investigación y la extensión en el contexto de las instituciones de educación superior. Como profesional tiene una exigencia propia que define una carrera académica, establecida en la Ley de Universidades, las Actas Convenio, y las normas y estatutos reglamentarios que ordenan la vida académica de la Universidad. Hasta ahora se ha caracterizado la migración del cuerpo docente universitario, en este apartado se abordan las particularidades académicas del profesor universitario que migró, en específico: en cuál universidad laboraba, cuál era su grado de instrucción al salir del país, las actividades realizadas, la dedicación que tenía, las investigaciones que desarrollaba. 
La muestra estaba conformada por docentes de más de 14 universidades, la mayoría de ellas del sector público (89\%), con un sesgo importante de docentes de la Universidad Central de Venezuela (42,1\%).

Tabla 8. Universidad en la que trabajaba

\begin{tabular}{|c|c|c|}
\hline & $\mathrm{N}$ & $\%$ \\
\hline Universidad Central de Venezuela & 157 & 42,1 \\
\hline Universidad Pedagógica Experimental Libertador & 31 & 8,3 \\
\hline Universidad de los Andes & 29 & 7,8 \\
\hline Universidad Simón Bolívar & 23 & 6,2 \\
\hline Universidad Católica Andrés Bello & 21 & 5,6 \\
\hline Universidad del Zulia & 18 & 4,8 \\
\hline Universidad Centro Occidental Lisandro Alvarado & 15 & 4,0 \\
\hline Universidad Nacional Abierta & 15 & 4,0 \\
\hline Universidad de Oriente & 9 & 2,4 \\
\hline Universidad Nacional Experimental de Guayana & 9 & 2,4 \\
\hline Universidad Metropolitana & 8 & 2,1 \\
\hline Universidad de Carabobo & 6 & 1,6 \\
\hline Universidad Nacional Experimental Francisco de Miranda & 5 & 1,3 \\
\hline Universidad Nacional Experimental Simón Rodríguez & 5 & 1,3 \\
\hline Otras & 22 & 5,9 \\
\hline Total & 373 & \\
\hline
\end{tabular}

Fuente: Elaboración propia

La crisis universitaria derivada de la falta de presupuesto, salarios bajos y el deterioro de las condiciones institucionales son aspectos que inciden en que la mayoría del personal docente encuestado proceda de universidades públicas (autónomas y experimentales). Como se señaló antes, las universidades venezolanas tienen el mismo presupuesto desde el año 2007, los cambios en ese renglón se hacen de forma unilateral de parte del gobierno nacional y más del $90 \%$ de lo asignado se utiliza para cancelar sueldos del personal. Las asignaciones para investigación son exiguas o simbólicas. Todo ello dificulta la labor de docencia e investigación. Los aumentos de los sueldos son decididos de forma unilateral por el ejecutivo o con arreglos de sindicatos afectos al gobierno. A esto se le agrega que las universidades autónomas tenían suspendidas las elecciones de autoridades por una decisión del Tribunal Supremo de Justicia desde el año 2011. Entonces, al clima de conflictividad nacional se le agrega al deterioro de las condiciones de trabajo y de funcionamiento de la institución, todo ello es el escenario propicio para emprender un nuevo proyecto de vida fuera de la universidad y del país.

Solo el 18\% del cuerpo docente consultado indicó que eran contratados, eso significa que la mayoría de ellos era personal fijo de las universidades, las universidades contaban con ese grupo para realizar labores de docencia e investigación en los próximos años. Esta delicada situación se hace más grave cuando se examina la dedicación que ellos indican que tenían en las instituciones donde laboraban. 
Salcedo, A. y Uzcátegui Pacheco, R. A.

Docentes universitarios migrantes: una mirada cuantitativa a un problema cualitativo

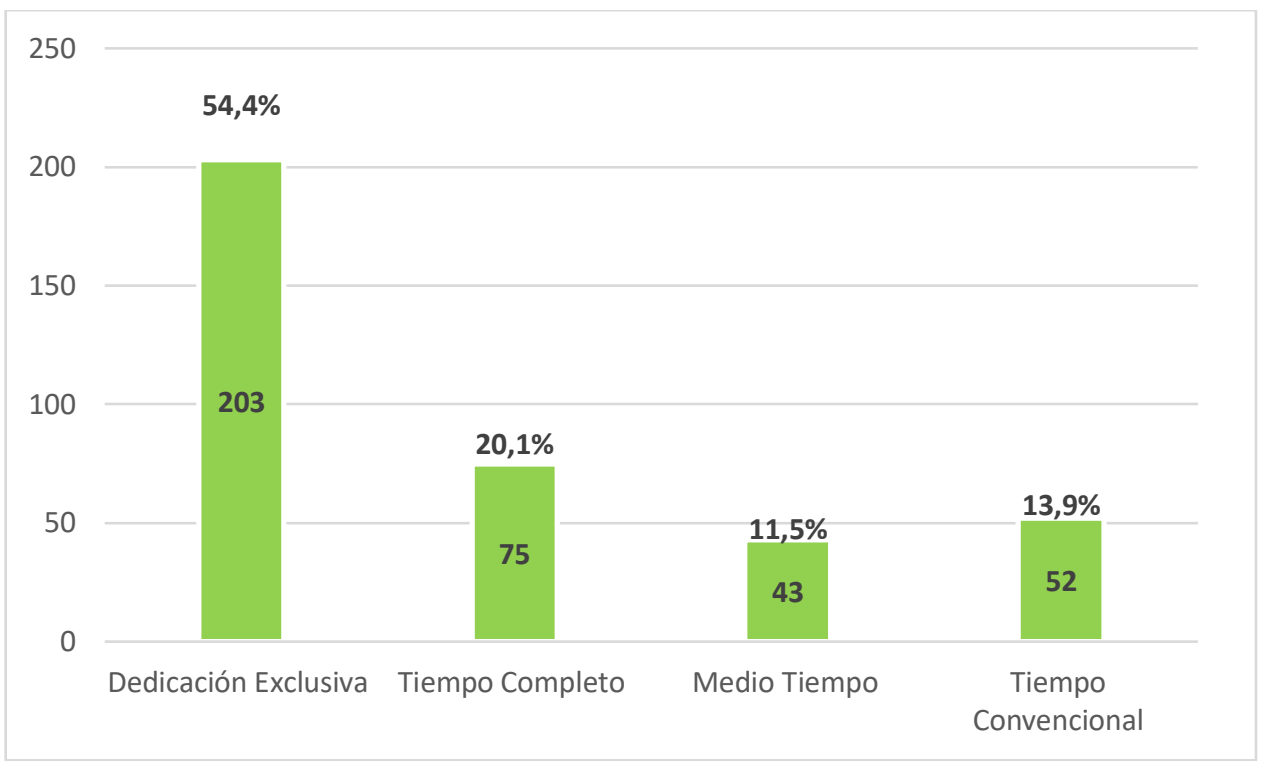

Gráfico 3. Dedicación en la universidad

Fuente: Elaboración propia

La mayoría de los sujetos de la muestra indicó que eran docentes a dedicación exclusiva en sus labores universitarias, son docentes que dedicaban 40 horas semanales a la universidad y, de acuerdo con las normativas vigentes, únicamente trabajan en una institución de educación superior. Si a ellos se agregan los que manifiestan tener una dedicación a Tiempo Completo, se tiene que más del $74 \%$ de los que emigraron dedicaban al menos 36 horas semanales a la universidad. Eso significa una pérdida de más de 10.000 horas semanales de actividades entre los docentes de esas dos dedicaciones. Una descapitalización importante de las universidades venezolanas en relación al cuerpo docente de planta a máxima dedicación, conforme las condiciones reglamentarias establecidas en la materia.

Conforme el desarrollo académico alcanzado al momento de salir del país, la mayoría señaló que estaba en el escalafón de Titular, máxima jerarquía de la carrera académica en Venezuela. Conforme las respuestas dadas, la distribución es la siguiente: 
Salcedo, A. y Uzcátegui Pacheco, R. A.

Docentes universitarios migrantes: una mirada cuantitativa a un problema cualitativo

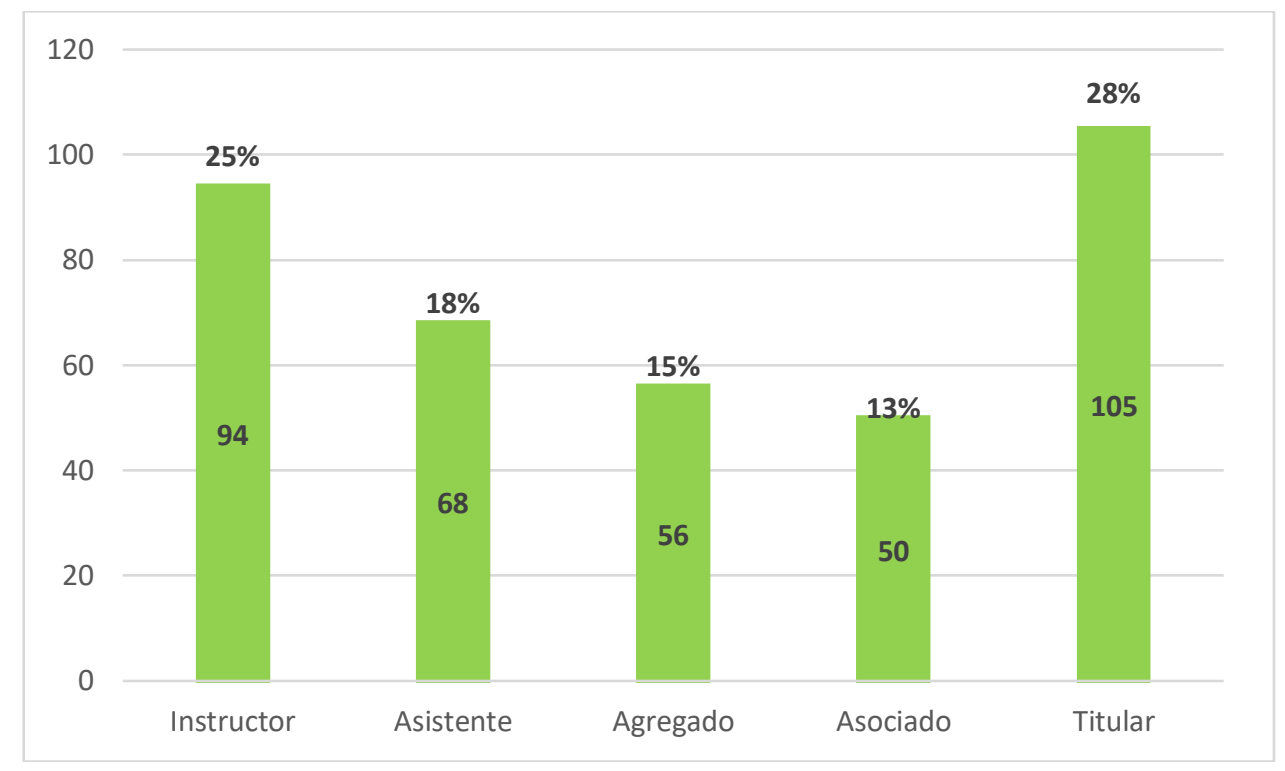

Gráfico 4. Nivel de escalafón en la jerarquía académica universitaria Fuente: Elaboración propia

Si bien la mayoría de la muestra manifestó estar en el escalafón de Titular, un grupo de similar magnitud son los que indicaron que estaban en el escalafón de Instructor. Significa que se fue parte del cuerpo docente que inicia la carrera académica y una parte que la finalizaba. A los primeros probablemente le quedaban al menos veintitrés años de servicio en la universidad (instructores) y a los titulares cinco años o menos. Una posible merma en años de servicios a la universidad venezolana.

Si a los del escalafón de Instructor se le suman los que están en el escalafón siguiente (Asistente), se tiene una pérdida de $43 \%$ de la generación de relevo del personal docente universitario. Si se considera que reglamentariamente para optar a la categoría de Titular es necesario estar al menos 15 años en la universidad, este es un grupo de docentes tenia las posibilidad desarrollar su carrera académica hasta ese último escalafón; siempre que contara con las condiciones personales, institucionales y sociales para lograrlo.

Al consultar sobre el nivel de instrucción alcanzado al momento de salir del país, la mayoría de los consultados indicó que tenía doctorado. En la tabla 9 se muestra la distribución del nivel de instrucción logrado según lo indicado por el grupo encuestado.

Tabla 9. Nivel de instrucción alcanzado al momento de salir de Venezuela

\begin{tabular}{|l|r|r|}
\hline Titulo & \multicolumn{1}{|l|}{ N } & \multicolumn{1}{|c|}{} \\
\hline Licenciado / Médico / Ingeniero (o título equivalente de pregrado) & 43 & $12 \%$ \\
\hline Especialista & 39 & $10 \%$ \\
\hline Magister & 116 & $31 \%$ \\
\hline Doctor & 175 & $47 \%$ \\
\hline
\end{tabular}




\begin{tabular}{l|l|l|} 
Total & 373 & $100 \%$ \\
\hline
\end{tabular}

Fuente: Elaboración propia

La tabla indica que el $78 \%$ de las personas que conforman la muestra tenían al menos el título de Magister. La salida del país de este grupo significa una merma significativa en años de formación que invirtió la universidad venezolana, con efectos negativos en los estudiantes y en cuerpo docente de menor formación y escalafón, de los cuales fungirían como formadores.

A este grupo de docentes migrante se le consultó sobre los años de servicio que tenían en su institución al momento de salir del país, de acuerdo a lo señalado la universidad venezolana habría perdido 5878 años de experiencia docente y de investigación, que es la suma del total de años de servicio del grupo. En promedio son 15,51 años de experiencia por profesor, con una desviación estándar de 11,02, lo cual indica que es un grupo bastante heterogéneo en cuanto a su experiencia docente. Tomando en consideración lo anterior y sobre la base de la legislación venezolana, según la cual un docente universitario se jubila a los 25 años de servicio, se excluyeron los casos que tenían 24 años o más trabajando en su institución y se calculó el tiempo restante para tener derecho a la jubilación. Los resultados se muestran en el gráfico 5.

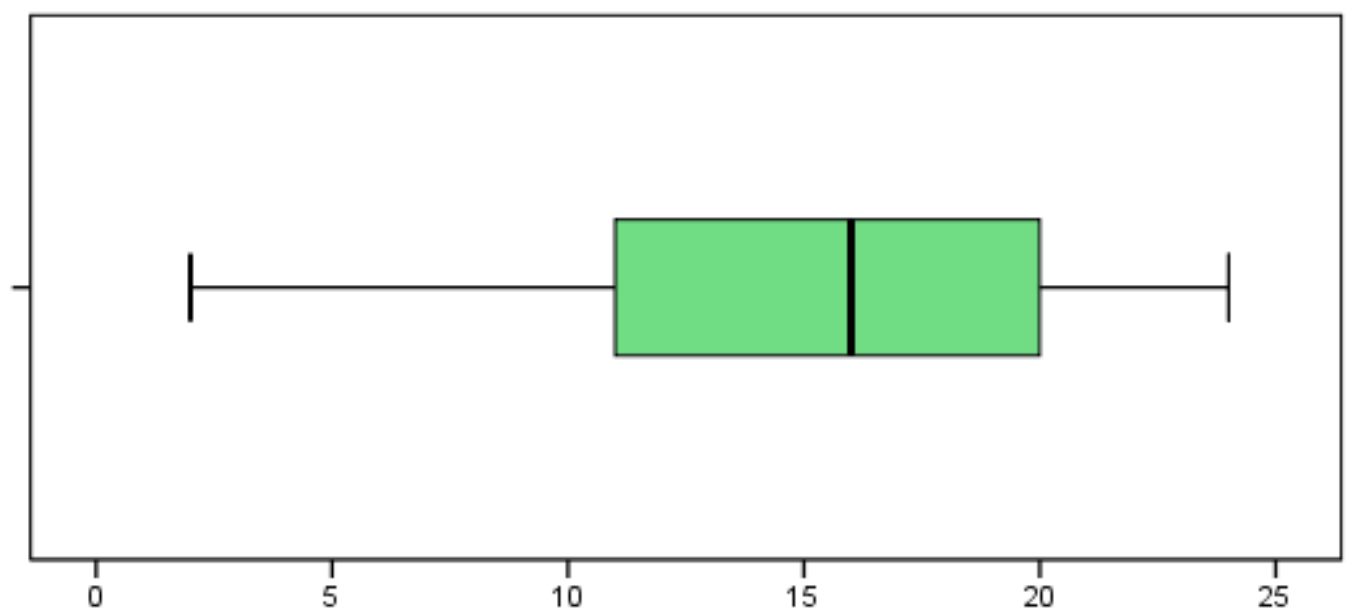

Gráfico 5. Nivel de escalafón en la jerarquía académica universitaria Fuente: Elaboración propia

Este grupo suma 2532 años de experiencia con un promedio de 9,7 años para cada uno y una desviación típica de 6,11 años. En cuanto a tiempo restante para la jubilación, al 75\% le quedaban entre 9 y 24 años de servicio en su institución antes de poder optar a ese derecho. Mientras que al 50\% le restan entre 14 y 24 años de servicio a la institución. Por el promedio en años de servicio y el tipo restante para la jubilación, este grupo parece estar conformado por docentes que estaban comenzando o habían avanzado en su carrera docente, es parte de los docentes que 
en los próximos años liderarían la docencia y la investigación en sus universidades. Todos ellos suman un total de 3993 años que dejaron de trabajarse en la universidad venezolana, con un promedio de 15,3 años por profesor y una desviación estándar de 6,11 años. Todos estos números sugieren una pérdida significativa en años de experiencia docente y de investigación, así como una perdida mayor en años que este grupo consultado podría laborar en la universidad venezolana.

Al grupo participante también se les consultó si participaban de líneas o grupos de investigación en la universidad donde laboraban. La mayoría señalo que sí, que tenían y participaban en líneas de investigación.

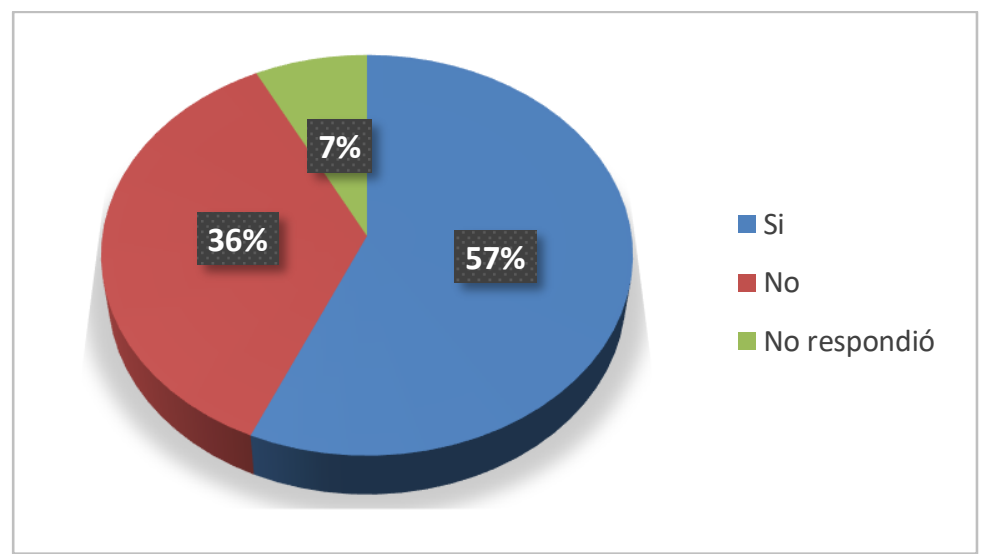

Gráfico 6. Actividad de la línea de investigación al momento de migrar Fuente: Elaboración propia

De acuerdo con lo manifestado por el grupo consultado, la mayoría de estas líneas de investigación cerraron al momento que salieron del país, lo que probablemente representa una disminución sustantiva en la capacidad investigadora y de innovación de la universidad venezolana, así como una disminución en la publicación de artículos. Van Noorden (2014) señala que Venezuela es el único país sudamericano cuya producción científica está disminuyendo, al caer el número de publicaciones citables en un 29\% entre 2009 y 2013. Al examinar los países latinoamericanos con mayor producción científica en el Scimago Journal \& Country Rank (SCIMAGO LAB, 2018) se encuentra que Venezuela pasó de ocupar el quinto lugar en 1999 al décimo puesto en 2018. Perú en 1999 producía el 20\% de los artículos que Venezuela, en 2018 supera la producción de Venezuela en más del doble. Ecuador en 1999 ocupaba el decimotercer lugar de la región en producción de artículos, en 2018 ocupa el sexto lugar de la región triplicando la producción de artículos de Venezuela. Todo esto da cuenta de la merma en la producción académica de las universidades venezolanas, principales productoras de artículos científicos del país, la cual puede seguir bajando por la salida continuada de universitarios.

Es interesante saber, considerando el perfil que se viene construyendo a partir de la muestra recolectada, si estos migrantes venezolanos continúan ejerciendo o 
laborando en el contexto universitario en los países de acogida. Los datos obtenidos informan que no, la mayoría de los ahora migrantes no continúan en la docencia universitaria, muchos han tenido que redefinirse profesionalmente, emprender un nuevo proyecto de vida, dedicarse a otras labores, muchas, radicalmente distintas a las funciones universitarias.

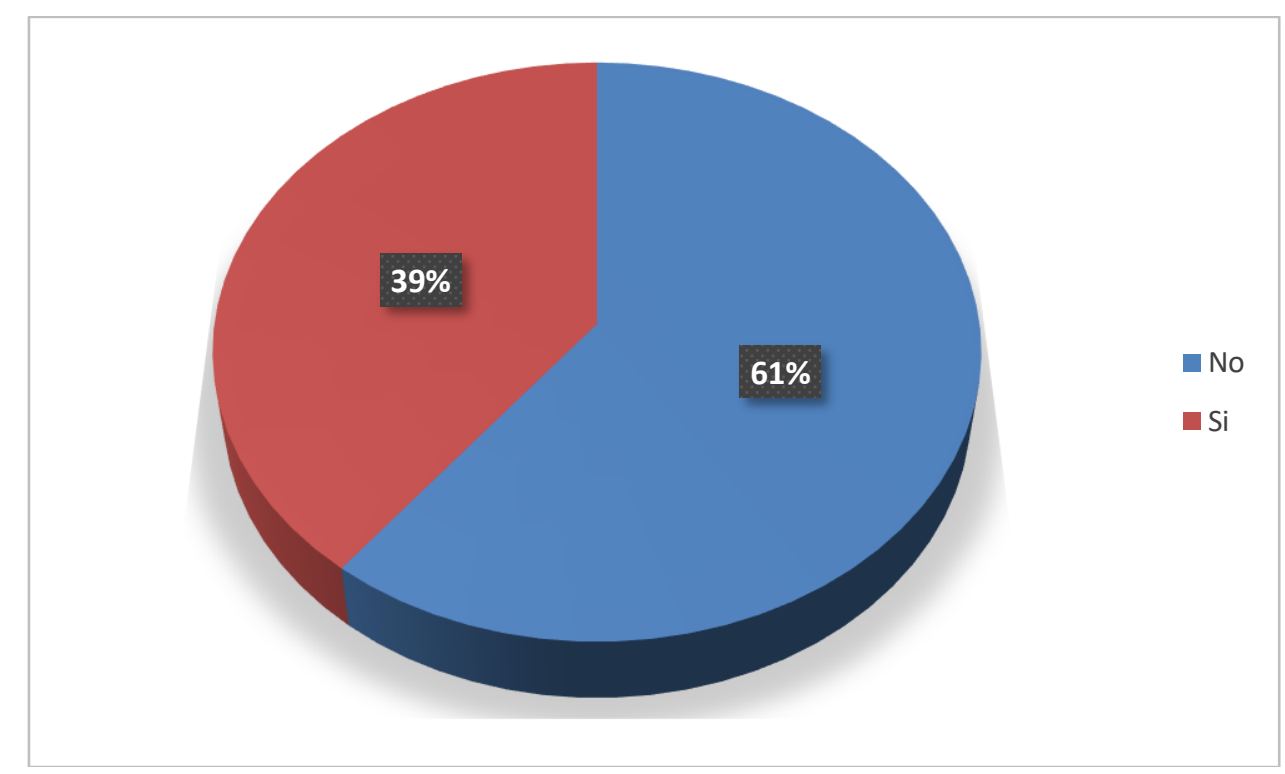

Gráfico 7. Trabaja actualmente como profesor universitario en el país receptor Fuente: Elaboración propia

La muestra de 373 sujetos, hoy 147 señalaron que trabajan en el contexto universitario en los países receptores y muchos de ellos afirman continuar con sus líneas de investigación, al participar en equipos para la formación de nuevos talentos en los países receptores. Otros, la mayoría, 226 señalaron que no trabajan en actividades académicas universitarias.

Indistintamente de si trabaja o no como profesor universitario, la mayoría opina que su situación de vida es mejor o mucho mejor al compararla con la que tenía al momento de salir de Venezuela. 
Salcedo, A. y Uzcátegui Pacheco, R. A.

Docentes universitarios migrantes: una mirada cuantitativa a un problema cualitativo

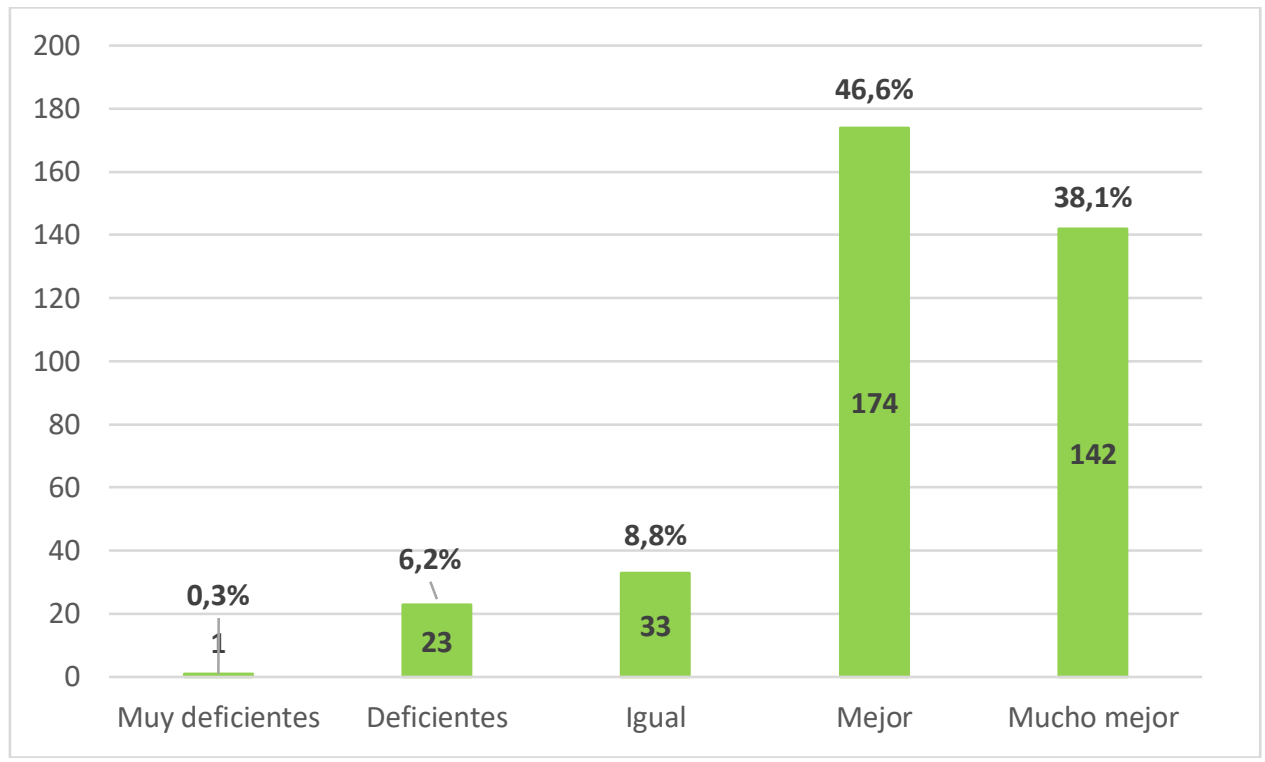

Gráfico 8. Situación de vida actual respecto a la que tenía al momento de salir de Venezuela

Fuente: Elaboración propia

La única persona que señala que en la actualidad sus condiciones de vida son muy deficientes respecto a las que tenía en Venezuela señala: En Venezuela tenía apartamento propio, sin hipoteca, 3 habitaciones, 2 baños y puesto de estacionamiento, carro propio pagado. Aquí vivo en una habitación alquilada y no tengo carro. Sin duda es un cambio radical en lo que respecta a su situación habitacional. Son los cambios que debe sufrir el migrante. Este tipo de situaciones en ocasiones están vinculadas con el tiempo que tienen el migrante en el país de acogida. Conseguir unas buenas condiciones de vida en un nuevo país suele llevar su tiempo, más todavía si la migración no fue planificada con suficiente tiempo y recursos.

\section{CONCLUSIONES}

El fenómeno de la migración en Venezuela es de reciente data. De un país que durante décadas recibió migrantes de distintos continentes, en los últimos años pasó a ser un país expulsor. Eso hace necesario el estudio de la migración desde diversas perspectivas. En este trabajo se estudia la migración del profesorado universitario venezolano, con la finalidad de distinguirlo y caracterizarlo dentro de la dinámica migratoria que afecta a la población venezolana. Dadas la forma como se recolectaron los datos, esta es solo una primera aproximación a las características de esos migrantes y su posible impacto en la dinámica institucional y académica de la universidad venezolana.

Conceptualmente, el grupo en estudio es caracterizado como migración intelectual forzada, que se han visto en la necesidad de salir de su país de origen y modificar su profesión, inicialmente, la carrera académica. En contraste con la revisión teoría realizada, el grupo objeto de estudio, expresa una dinámica migratoria de un sector 
profesional e intelectual no necesariamente movido por el mercado global de recursos humanos, sino por la ruptura de las condiciones de vida y laborales del país de origen. Hecho que hace que no sea un fenómeno individual, sino masivo, el cual ha sido reconocido por organismos internacionales como la Oficina del Alto Comisionado de las Naciones Unidas para los Derechos Humanos. Además de la salida masiva de ciudadanos, este organismo señala que es preocupante la situación de los derechos humanos en Venezuela y precisa, entre otros problemas, los siguientes: (a) desconocimiento de la crisis por parte de las autoridades; (b) denuncias de asesinatos durante la actuación de las fuerzas de acciones especiales; (c) deterioro del sistema de salud; (d) restricciones a la libertad de expresión y prensa; (e) aumento de la exclusión escolar por la crisis; (f) colapso de los servicios públicos; (g) criminalización de la protesta (ONU, 2019). La crisis institucional y humanitaria de Venezuela es real.

La muestra estudiada de docentes migrantes universitarios de Venezuela es fundamentalmente venezolanos, casados o con pareja, jóvenes o en edad económicamente activa para el desarrollo de su carrera académica, con residencia en la Gran Caracas (Caracas y ciudades dormitorio). En cuanto al sexo se dividen exactamente en $50 \%$ y menos de un tercio tiene una segunda nacionalidad.

Este grupo del personal docente universitario migrante actualmente vive fundamentalmente con sus esposo/esposa e hijos y ha dejado en Venezuela una parte de su familiar nuclear, madre/padre, abuelos. El proceso migratorio parece haber recompuesto las relaciones familiares de este grupo de migrantes, marcada por las personas con las que actualmente viven y los que están lejos.

La mayoría del grupo estudiado salió de Venezuela en el periodo 2015 - 2018 y se ha desplazado hacia España, Ecuador, Chile, Colombia, Estados Unidos y Argentina, siendo Sudamérica la región con mayor recepción de venezolanos. Estiman que el tiempo que pueden pasar en el país de acogida es de al menos tres años, aunque las posibilidades de retorno dependen de los cambios, en lo político y económico, que se puedan dar en Venezuela. La decisión de retornar, al igual que la de migrar, no es solo una decisión personal, suele involucrar al resto del grupo familiar y tener vinculaciones económicas. Cuando están dadas las condiciones en el país de origen, la familia regresa con las mayores reservas económicas posibles, de manera que el retorno no es un fracaso sino un éxito migratorio (Stark y Bloom, 1985).

Las principales razones para migrar son las políticas, económicas, de inseguridad y laborales. Estás razones tienen como punto común la crisis socio política que vive el país, a partir de la imposición de un proyecto político de carácter hegemónico que cercenó las libertades ciudadanas y destruyó la institucionalidad democrática liberal para imponer una nueva casta política-militar unipartidista. Todo ello ha llevado a una crisis humanitaria compleja que viven los venezolanos en general y que ha motivado a grupos importantes de docentes universitarios a migrar para buscar condiciones básicas para la vida. 
En cuanto a sus características académicas, los integrantes de este grupo eran miembros del personal docente y de investigación de universidades públicas, ubicadas en Caracas, fundamentalmente de la Universidad Central de Venezuela y con estabilidad laboral (puesto fijo), tiempo completo o dedición exclusiva. Aunque en el grupo consultado hay miembros del personal docente de todos los escalafones, destacan los nivel Instructor (comenzando la carrera académica) y Titular (finalizándola). Indistintamente del escalafón la casi totalidad de esta muestra tienen estudios de postgrado, casi la mitad tenían en su hoja de vida la condición de doctor, con líneas de investigación activa en su universidad para el momento de salir del país. Aunque en el país de acogida no forman parte del personal docente de universidades, consideran que tienen mejores condiciones de vida al compararla con las que tenían en Venezuela.

Los resultados indican que la universidad venezolana parece estar sufriendo una pérdida importante de su talento. Tanto en formación, como por los años de experiencia y tiempo de servicio que le faltaba para optar a la jubilación, este grupo es una pérdida significativa para la universidad venezolana en docencia e investigación. Parece que ha salido parte de la generación del personal docente que debía asumir mayores responsabilidades en los próximos 10 o 15 años. Seguramente todos serán reemplazados por jóvenes talentosos, con ganas de trabajar, pero que daría los primeros pasos en la carrera académica; por lo cual debe cumplir su ciclo de formación. Deben hacer estudios de postgrado, sin incentivos económicos, con un país con hiperinflación y con un sueldo que no le alcanza para cubrir ni siquiera la canasta alimentaria. Pero también emigró parte del cuerpo docente que debía formar la generación de relevo de las universidades venezolanas. Se trata del grupo que estaba en el escalafón Titular, con maestría y doctorado, llamado a ayudar en la formación de los jóvenes talentosos que inicien la carrera académica en las universidades y hacen estudios de postgrado.

Aunque en Venezuela quedan docentes resilientes, que defiende la universidad de los embates del régimen en pro de la formación de recursos humanos especializados, no hay duda que la salida de los profesionales que conforman la muestra estudiada deja a la universidad venezolana en muy malas condiciones para enfrentar los retos que se le avecinan; aunque se produzca un cambio a corto plazo en la política del Estado respecto a las universidades.

Entonces, pareciera que la generación de docentes universitarios que tendrá la responsabilidad de formar a los futuros profesionales universitarios serán aquellos jóvenes que opten por quedarse en el país y ejercer la docencia, con el compromiso adicional de formarse en los programas de postgrado que queden activos en Venezuela. Esta sería una situación similar a la vivida por la universidad venezolana a comienzo de los sesenta.

El fenómeno de la migración es complejo y multifactorial y no puede verse como grupos de personas que cambian su lugar de residencia. La muestra estudiada sugiere que es un proceso complejo que involucra a la familia, políticas de Estado, 
factores económicos y culturales, que afecta tanto al país de salida como al de acogida. En este trabajo se ha hecho una primera aproximación para cuantificar y describir la migración del personal docente universitario. Pero es necesario profundizar en las razone de su migración, pero también, cómo se integran al país de acogida, en general y al mercado laboral, con particular énfasis en su reinserción en el mundo universitario.

\section{REFERENCIAS}

Alto Comisionado de las Naciones Unidas para los Refugiados (ACNUR) (2019). Situación en Venezuela. https://www.acnur.org/situacion-en-venezuela.html

Arocena, R. y Judith, S. (2006). Brain Drain and Innovation Systems in the South, International Journal on Multicultural Societies, 8(1). UNESCO. En: OIM. (2016). Migración calificada y desarrollo: desafíos para América del Sur. Cuadernos Migratorios N7. Buenos Aires: OIM.

Baeninger, R. y Jarochinski Silva, J. C. (2018). A imigracao quialificada venezuelana do seculo XXI: um estudo a partir dos espacos da migracao de trabalhadores do conhecimiento da Venezuela no Brasil. En: Migracoes Venezuelanas. Universidade Estadual de Campinas.

Cabieses, B., Bernales, M. y McIntyre, A. M. (eds) (2017). La migración internacional como determinante social de la salud en Chile: evidencia y propuestas para políticas públicas. Chile: Universidad del Desarrollo.

Castillo Crasto, T. \& Reguant Álvarez, M. (1970). Percepciones sobre la migración venezolana: Causas, España como destino, expectativas de retorno. Migraciones. Publicación del Instituto Universitario de Estudios sobre Migraciones, 41, 133163. https://doi.org/10.14422/mig.i41.y2017.006.

Cohen, J. (2001). Transnational migration in rural Oaxaca, Mexico: dependency, development and the household. American Anthropologist, 103(4), 954-967.

Consultores 21 (2019). Diáspora. Servicio de análisis de entorno $\mathrm{N}^{0} 7$. Cobertura Urbano Rural. https://tinyurl.com/yxsuclzr

Davidson, A. (2003). Ciudadanía y Migración: ¿Derechos para aquéllos sin pertenencia? Anales de la Cátedra Francisco Suárez, 37 (2003), 35-55.

De la Vega, I. y Vargas, C. (2014). Emigración intelectual y general en Venezuela: una mirada desde dos fuentes de información. Revista Electrónica Latinoamericana de Estudios Sociales, Históricos y Culturales de la Ciencia y la Tecnología, año 2014, N

De la Vega, I. (2003). Emigración intelectual en Venezuela: el caso de la ciencia y la tecnología. Interciencia, 28(5), 259-267. https:/ tinyurl.com/y6aatn2o. 
Salcedo, A. y Uzcátegui Pacheco, R. A.

Docentes universitarios migrantes: una mirada cuantitativa a un problema cualitativo

Descifrado.com (2020, 08 de marzo). Scharifker: Existe un 40\% de deserción de profesores y alumnos en las Universidades. https:/ / tinyurl.com/y64jmzr8

Dumont, J. y Spielvogel, P. (2008). La migración de retorno una nueva perspectiva. En: OCDE, Ministerio de Trabajo e Inmigración (Ed.) Perspectivas de las migraciones internacionales. Madrid: Primera

Castillo Crasto, T. \& Reguant Álvarez, M. (1970). Percepciones sobre la migración venezolana: Causas, España como destino, expectativas de retorno. Migraciones. Publicación del Instituto Universitario de Estudios sobre Migraciones, 41, 133163. https://doi.org/10.14422/mig.i41.y2017.006

Echeverry Hernández, A. A. (2011). Análisis de la migración venezolana a Colombia durante el gobierno de Hugo Chávez (1999-2011). Identificación de capital social y compensación económica. Revista de Análisis Internacional, 4. https://revistas.utadeo.edu.co/index.php/RAI/article/view/84

Feline Freier, L. y Parent, N. (2019). The Regional Response to Venezuelan Exodus. Current History 118, 805.

Fundação Getulio Vargas. Diretoria de Análise de Políticas Públicas. - Rio de Janeiro (2020). A economia de Roraima e o fluxo venezuelano: evidências e subsídios para políticas públicas. https:// data2.unhcr.org/es/documents/details/73853

García Arias, M. F. y Restrepo Pineda, J. E. (2019). Aproximación al proceso migratorio venezolano en el siglo XXI. Hallazgos, 16 (32), 63-82. https://dx.doi.org/10.15332/2422409x.5000

Ibarra Lampe, M. C. y Rodríguez, C. (2011). Invirtiendo en el fututo: una mirada del migrante calificado en el proceso migratorio de Venezuela hacia Australia. Temas de Coyuntura, 63, 69-106.

Instituto Nacional de Estadística (INE) (2019). Estimación de personas extranjeras residentes en Chile. 31 de diciembre de 2018. https://tinyurl.com/y4x3cqah

Izcara, P. (2010). Redes migratorias o privación relativa: la etiología de la emigración tamaulipeca a través del programa H-2 a . Relaciones, XXXI (122), 245-278. Zamora, El Colegio de Michoacán.

Jamrisko, M. y Saraiva, C. (2019). The World's Most Miserable Economy Has SevenFigure Inflation. Bloomberg. https://tinyurl.com/y5964f46 
Mahlke, H. y Yamamoto, L. (2017). El desplazamiento venezolano: un desafío para Brasil. Revista Migraciones Forzadas, (56). https://www.fmreview.org/es/latinoamerica-caribe/mahlke-yamamoto

Mateo, C., y Ledezma, T. (2006). Los venezolanos como emigrantes. Estudio exploratorio en España. Revista Venezolana de Análisis de Coyuntura, XII (2), 245267. http:// www.redalyc.org/pdf/364/36412214.pdf

Méndez, G. (2014). Los docentes universitarios migran por situación laboral. El Universal.

Morles, V., Medina R. E. y Álvarez, B. N. (2003) La educación superior en Venezuela. Informe 2002. https://unesdoc.unesco.org/ark:/48223/pf0000131594

IESALC-UNESCO.

Organización para la Cooperación y el Desarrollo Económicos (OCDE) (2019). International Migration Outlook 2019. https://tinyurl.com/y4lbz2uz

Organización Internacional para las Migraciones (OIM). (2018). Tendencias migratorias en las Américas. República Bolivariana de Venezuela. Buenos Aires: OIM.

Organización Internacional para las Migraciones (OIM). (2019). Plan de Acción Regional. Para el fortalecimiento de la respuesta a los flujos migratorios recurrentes de nacionales en Venezuela a América del Sur, Norteamérica, América Central y el Caribe. Buenos Aires: OIM.

Organización de Naciones Unidas (ONU) (2019). Informe oral de actualización sobre la situación de derechos humanos en la República Bolivariana de Venezuela. $40^{\circ}$ período de sesiones del Consejo de Derechos Humanos. https://www.ohchr.org/SP/NewsEvents/Pages/DisplayNews.aspx?NewsID=24 374\&LangID=S

Oso C., L., y Villares, M. (2005). Mujeres inmigrantes lationamericanas y empresariado étnico: dominicanas en Madrid, argentinas y venezolanas en Galicia. Revista Galega de Economía, 14 (1- 2), 0. http://www.redalyc.org/html/391/39114215/

Páez, T. (2010). La diáspora venezolana: políticas públicas y desarrollo. http:/ / caelum.ucv.ve/bitstream/123456789/16044/1/PonenciaTom $\%$ C3\%A1s\%20Pa $\%$ C3\%A9z.pdf

Parra Sandoval, M. C. (2003). La profesión académica en venezuela: de los «catedráticos» a los profesores universitarios. Cuadernos del Cendes, 20(53), 93-120. http://ve.scielo.org/scielo.php?script=sci_arttext\&pid=S101225082003000200008\&lng=es\&tlng=es. 
R4V (2019). Refugiados y migrantes venezolanos en la región. Hasta diciembre de 2019. América Latina y el Caribe. http://R4V.info

Requena, J. y Caputo, C. (2016). Pérdida de talento en Venezuela. Migración de sus investigadores. Interciencia. Julio, 2016, 41(7), Pp. $444-453$.

Rivas, L. M. (2009). ¿Irse o quedarse? La migración venezolana en la narrativa del Siglo XXI. https://bit.ly/2Oje8UU

RMRP (2020). Refugee and Migrant Response Plan 2020. January - December 2020. RMRP 2020. https:/ / data2.unhcr.org/es/documents/details/73277

SCIMAGO LAB (2018) SCImago, Journal and Conutry Rank. https://www.scimagojr.com/.

Stark, O. y Bloom, D. (1985). The New Economics of Labour Migration. American Economic Review (75), 173-178.

Stark, O. y Taylor, E. (1991). Migration incentives, migration tipes: the role of relative deprivation. The Economic Journal, 101(408), 1163-1178. Royal Economic Society.

Organización de las Naciones Unidas para la Educación, la Ciencia y la Cultura (UNESCO) (2019). Migración, desplazamiento y educación: construyendo puentes, no muros. Informe de seguimiento de la educación en el mundo. Francia. http://www.unesco.org/open-access/terms-use-ccbysa-en

Uzcátegui Pacheco, R. A., Guzmán Guerra, W., Bravo Jauregui, L. (2018). El proceso migratorio y el vaciamiento de la institucionalidad educativa escolar en Venezuela. Revista electrónica de investigación educativa sonorense. Año X. Número Especial, pp. 20-49. https://rediesonorense.wordpress.com

Vargas Ribas, C. (2018). La migración en Venezuela como dimensión de la crisis. Pensamiento Propio 47, 91 - 128.

Van Noorden, R. (2014). The impact gap: South America by the numbers. Nature 510 (7504), 202-203. https:// doi.org/10.1038/510202a

Zuñiga, G. (2011). La emigración de jóvenes en Venezuela: problemas y soluciones. Ponencia presentada en Seminario: “La Nueva Agenda de la Juventud Social demócrata en Venezuela: Retos y Desafíos". Caracas.

\section{AUTORES:}

\section{Audy Salcedo}

Licenciado en Educación mención matemáticas por la Universidad Central de 
Venezuela. Master en Enseñanza de la Matemática. Doctor en Educación. En la actualidad ejerce como profesor de Estadística Aplicada a la Educación en pre y postgrado de la Universidad Central de Venezuela. Profesor invitado del Doctorado en Educación de la Universidad Andrés Bello, Venezuela. En la Universidad Central de Venezuela ha ejercido diversos cargos de gestión universitaria: Coordinador Ejecutivo Programa de Cooperación Interfacultades, Jefe del Centro de Investigaciones Educativas, Jefe del Departamento de Estadística e Informática Aplicada a la Educación, Jefe de Cátedra de Métodos Cuantitativos. Ha publicado artículos de investigación, seleccionados con evaluación de pares, en 12 países. Editor Asociado de Areté, Revista Digital del Doctorado en Educación de la Universidad Central de Venezuela. Editor invitado del número especial para América Latina del Statistics Education Research Journal.

audy.salcedo@ucv.ve.

Orcid ID: https://orcid.org/0000-0002-9783-8509

Google Scholar: https://scholar.google.es/citations?user=dFInkAkAAAAJ\&hl=es

\section{Ramón Alexander Uzcátegui Pacheco}

Doctor en Humanidades (UCV, 2010). Licenciado en Educación (UCV, 2005); posdoctor en Filosofía y Ciencias de la Educación (UCV, 2016); Magíster en Investigación e Innovación Educativa (UNED-2019). Pasantía posdoctoral en la Universidad de Playa Ancha (Chile, 2018); Estancia de Investigación en el CEINCE (Soria-España, 2019); profesor en la Universidad de Playa Ancha, Chile (2018), Universidad Santo Tomas, Chile (2018), Universidad Andrés Bello, Chile (2019). Miembro del Grupo de Estudios "Enseñanza de la Historia, Ciudadanía y Educación" (UC, UNAB, UPLA - Chile); Miembro de la línea de Investigación Memoria Educativa Venezolana (UCV-Venezuela); Miembro de la Red Internacional América latina, África, Europa y el Caribe (ALEC - Universidad de Lemoges- Francia). Editor de la Revista de Pedagogía (UCV, 2016-2018); Investigador acreditado: PEIIVenezuela, Nivel II (2010-2015). Investigador registrado en Concytec-Perú (2018); Investigador con publicaciones en el área de la Educación, Pedagogía, Historia de la Educación, Textos Escolares.

razktgui@gmail.com

Orcid ID: $\underline{\text { https:/ / orcid.org/0000-0002-5669-6663 }}$

Google Scholar: https://scholar.google.es/citations?user=g-0-Y2wAAAAJ\&hl=es 